INFO ARTIKEL

Riwayat Artikel:

Diterima : 9 Juni 2019

Disetujui : : 10 Agustus 2019

\title{
GEOGRAFI
}

\section{TEKNOLOGI GEOSPATIAL UNTUK INVESTIGASI PENYERANGAN RATTUS ARGENTIVENTER SEBAGAI UPAYA MITIGASI LAHAN PERTANIAN}

\author{
Beben Graha Putra', Robet Tri Arjunet ${ }^{2}$ \\ ${ }^{1-2}$ Geografi, Fakultas Ilmu Sosial, Universitas Negeri Padang \\ $(\square)$ bebengp355@ gmail.com ${ }^{1}$
}

\begin{abstract}
ABSTRAK
Rattus argentiventer atau Tikus Sawah merupakan salah satu hama yang cukup merugikan para petani. Hal ini didasari oleh sifat Tikus Sawah yang Nocturnal sehingga sulit untuk diamati pergerakannya, bahkan tikus dalam semalam dapat menghabiskan Padi sebanyak 11-176 batang. Dengan melihat Landscape Ekologi dan fisiologis dari Tikus Sawah dapat menjadikan hubungan indikator dalam penyerangan hama. Tikus Sawah menyukai tempat yang kotor serta dipenuhi oleh semak belukar, karena merupakan tempat favorit dalam berkembang biak. Batas ruang gerak tikus apabila cukup tersedia makanan dan perlindungan, biasanya tidak lebih dari 100m dengan menyerang padi dimulai dari tengah sawah, tetapi apabila makanan tidak cukup maka tikus akan mengembara dan dapat mencapai jarak 3-5 $\mathrm{km}$. Tujuan penelitian untuk mengetahui distibusi titik lokasi penyerangan Hama Tikus Sawah, menentukan tingkat bahaya dan persentasi gagal panen, memahami hubungan bahaya penyerangan hama tikus dengan kondisi landscape ekologi pada lahan pertanian. Metode yang digunakan yaitu Kernel Density Estimation dan ditambah dengan metode Overlay. Berdasarkan hasil pengolahan dengan menggunakan GIS didapatkan persentase luas kerugian sebesar 46,258\%. Selain luas, didapatkan pula indikator yang menyebabkan terjadi nya kegagalan panen yaitu daerah yang berada didekat Irigasi serta pematang yang kotor tingkat kerusakan nya lebih tinggi.
\end{abstract}

Kata Kunci : Kernel Density Estimation, Rattus Argentiventer, Zona Ancaman

\section{PENDAHULUAN}

Tikus sawah Rattus argentiventer merupakan salah satu hama mengerat yang seringkali merugikan manusia, terutama di bidang pertanian salah satunya di lahan pertanian padi yang dapat menyebabkan tanaman puso atau gagal panen. Kehilangan hasil gabah akibat serangan hama itu hampir terjadi setiap musim tanam ,mulai dari proses semai sampai padi akan di panen bahkan juga di gudang penyimpanan, kerusakan tanaman padi karena serangan tikus umumnya terjadi pada fase vegetstif atau pada saat umur padi sewaktu muda, batang padi tersebut digit atau dipotong karna pada saat fase ini batang padi lebih cendrung berasa manis dibandingkan pada saat umur padi sudah tua.

Seekor tikus dapat merusak antara 11-176 batang padi per malam. Sedangkan pada fase generatif pada saat tikus bunting kemampuan merusak meningkat, menjadi 24-246 batang per malam, pada kerusakan berat biasanya hanya tersisa beberapa baris tanaman terutama pada bagian tepi (Direktorat Bina Perlindungan Tanaman,1992 dan 2011). 
Hal tersebut mengakibatkan kerusakan yang berat, Upaya pengendalikan tikus perlu disusun strategi pengendalian yang tepat sesuai dengan skala prioritas berdasarkan kategori serangan.

Salah satu analisis yang dipakai dalam penelitian ini ialah metode Kernel density. Kernel density merupakan fungsi matematika yang dikembangkan menjadi fungsi spatial untuk mengukur persebaran intensitas suatu titik dalam bidang dengan radius tertentu (Kloog dkk, 2009)

Tujuan akhir dalam penelitian ini ialah dalam rangka menyediakan informasi yang dapat digunakan sebagai dasar dalam membuat perencanaan dalam pengambilan kebijakan pengendalian tikus di Kecamatan Koto Tangah Kota Padang, maka dilakukan analisis dan identifikasi daerah penyebaran serangan tikus di Kecamatan Koto Tangah tersebut. Tikus menyerang padi pada malam hari. Pada siang hari tikus bersembunyi di dalam lubang pada tanggul tanggul irigasi, jalan sawah, pematang, dan daerah perkampungan dekat sawah. Pada periode sawah bera (setelah panen), sebagian besar tikus bermigrasi ke daerah perkampungan dekat sawah dan akan kembali lagi ke sawah setelah pertanaman padi menjelang generatif.

\section{METODOLOGI PENELITIAN}

Penelitian ini adalah penelitian deskriptif kuantitatif, dengan menggunakan data primer yang diambil survey lapangan, studi literatur, dan di analisis secara spasial. Penelitian ini dilaksanakan di Kelompok Tani Bungo Padi Rimbun, Kecamatan Koto Tangah, Kota Padang, Provinsi Sumatera Barat.

Alat yang digunakan dalam mengolah data yaitu menggunakan perangkat keras dan lunak. Perangkat keras seperti GPS, Laptop dan perangkat lunak menggunakan software Arcgis 10.2.

Analisis deskripsi digunakan untuk melihat sebaran titik tikus yang melakukan penyerangan. Analisis Spasial Statistik Kernel bertujuan untuk membahas indeks bahaya penyerangan hama tikus yang diperoleh dari hasil pengolahan Kernel
Density. Analisis overlay untuk menganalisis hubungan indeks bahaya dengan kenampakan citra kondisi eksisting dan data observasi lapangan.

\section{HASIL DAN PEMBAHASAN}

Dalam kasus ini menerapkan statistik GIS dalam pemahaman fenomena Spasial, Ekologi, terutama ekosistem Sawah, Dengan ketentuan variabel seperti Fisiologi tikus sawah, Pola penyerangan, Indikator lingkungan, habitat untuk kamuflase. Kondisi ini saling bersinergi dalam Jaringan ekosistem terhadap Pola penyerangan Tikus.

\section{- Sebaran Titik Penyerangan Hama Tikus}

Dari hasil survey lapangan dengan pengumpulan data primer lapangan dalam dua kali survey ke lokasi penelitian, pengumpulan titik koordinat penyerangan hama tikus di peroleh sebaran titik penyerangan seperti gambar 1 .

Dari peta di gambar 1 menjelaskan persebaran penyerangan hama tikus dengan riwayat kejadian. Pengambilan titik diambil 2 kali yaitu pada tanggal 4 Januari dan 28 Februari, dari 2 data ini terlihat perbedaan yaitu terjadi penambahan lokasi baru serangan hama tikus sehingga kerusakan yang terjadi semakin besar.

Pengambilan titik koordinat pada padi yang rusak karena serangan hama diolah menggunakan GIS dengan prinsip Kernel Density sehingga hasil dari pengolahan tersebut dapat menggambarkan bagaimana serangan hama tikus sawah (Rattus argentiventer) dari titik yang mengelompok tersebut akan tergambarkan pula intesitas penyerangan. Tikus sawah yang menyerang dimulai dari bagian tengah dan bergerak hingga padi pada sawah tersebut rusak. Tikus sawah aktif dimalam hari (nocturnal) dan pada siang hari mereka berlindung didalam lubang atau semak. Sehingga untuk mengamati penyerangannya secara langsung cukup sulit maka diperlukan peta hasil pengolahan Kernel Density agar dapat melihat daerah yang terdampak serta pola penyerangan.

Serangan tikus ini membentuk pola-pola tersendiri tergantung kondisi padi di sekitarnya. 
Pada kasus ini, terdapat perbedaan waktu panen yang menyababkan adanya sawah yang sudah dipanen letaknya berdekatan dengan sawah yang belum dipanen sehingga tikus sawah tersebut terus mencari padi-padi yang belum dipanen untuk merka makan. Apabila area padi yang merupakan sumber makanan mereka sudah habis, maka mereka akan mencari area lainnya sebagai tempat baru untuk memperoleh makanan, begitu seterusnya sehingga terbentuknya pola-pola penyerangan akibat aktivitas tikus sawah.

\section{- Tingkat Persentase Gagal Panen dan Penyerangan Hama Tikus Sawah}

Persebaran kerusakan dari hama tikus dianalisis menggunakan metode kernel density. Kernel density merupakan fungsi matematika yang kemudian dikembangkan dalam fungsi spasial untuk mengukur persebaran intensitas suatu titik dalam bidang dengan radius tertentu. Dari peta hasil pengolahan Kernel Density menghasilkan persebaran serta tingkat kerusakan yang terjadi. Pengamatan dilakukan selama 1 bulan dimulai dari Januari sampai Februari sehingga pola penyerangan bisa analisis pergerakannya. Dari pola penyerangan tersebut dapat memahami bagaimana arah pergerakan penyerangan nya seperti titik-titik kecil kerusakan menggambarkan lokasi penyerangan selanjutnya. Jika dilihat titik tersebut tidak lah jauh dari daerah yang mengalami kerusakan paling parah itu sesuai dengan fisiologis tikus sawah yang telah dijelaskan sebelumnya. Untuk lebih jelasnya dapat ilihat pada gambar 2 .

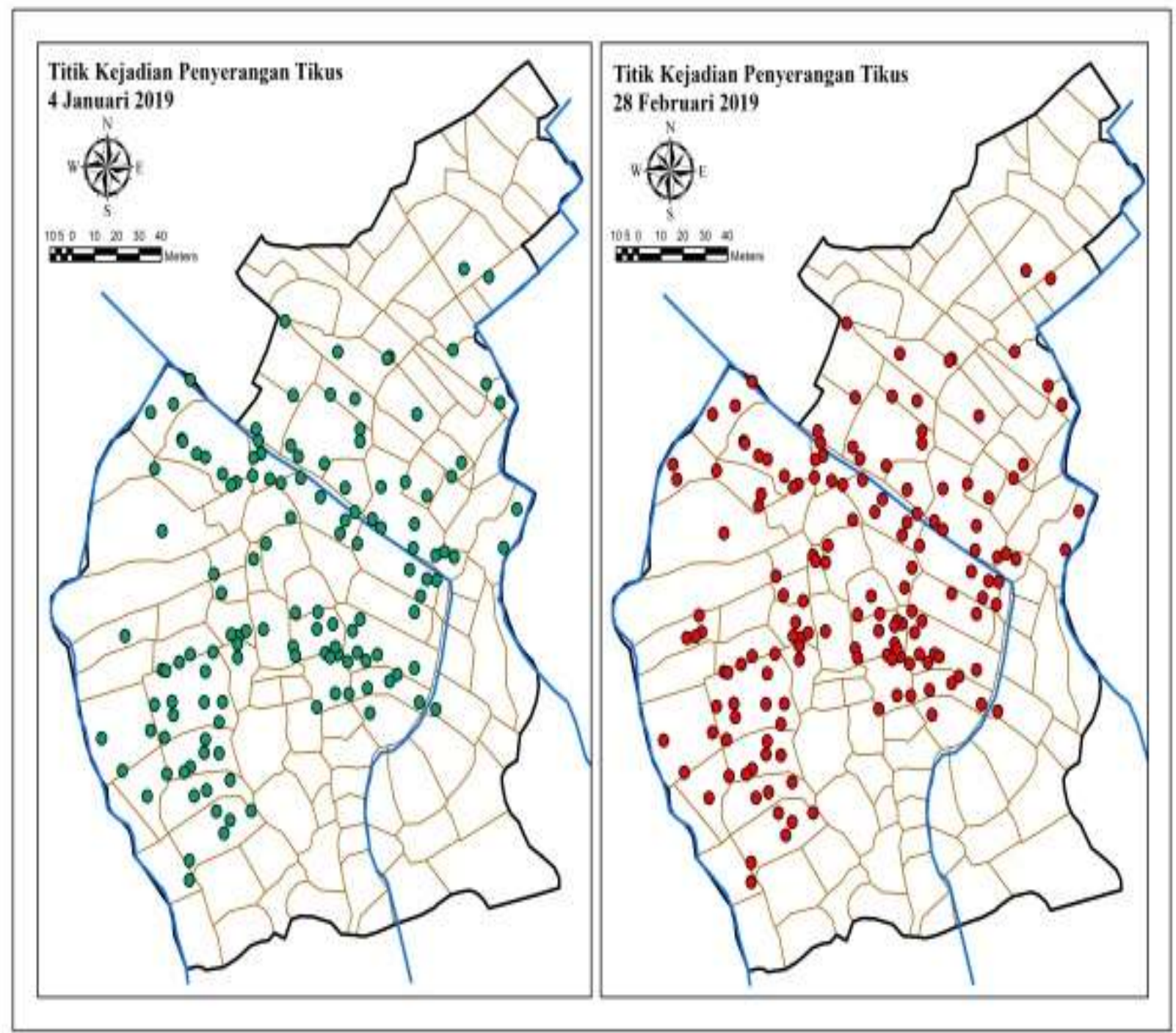

Gambar 1. Peta persebaran Hama bulan Januari dan Februari 

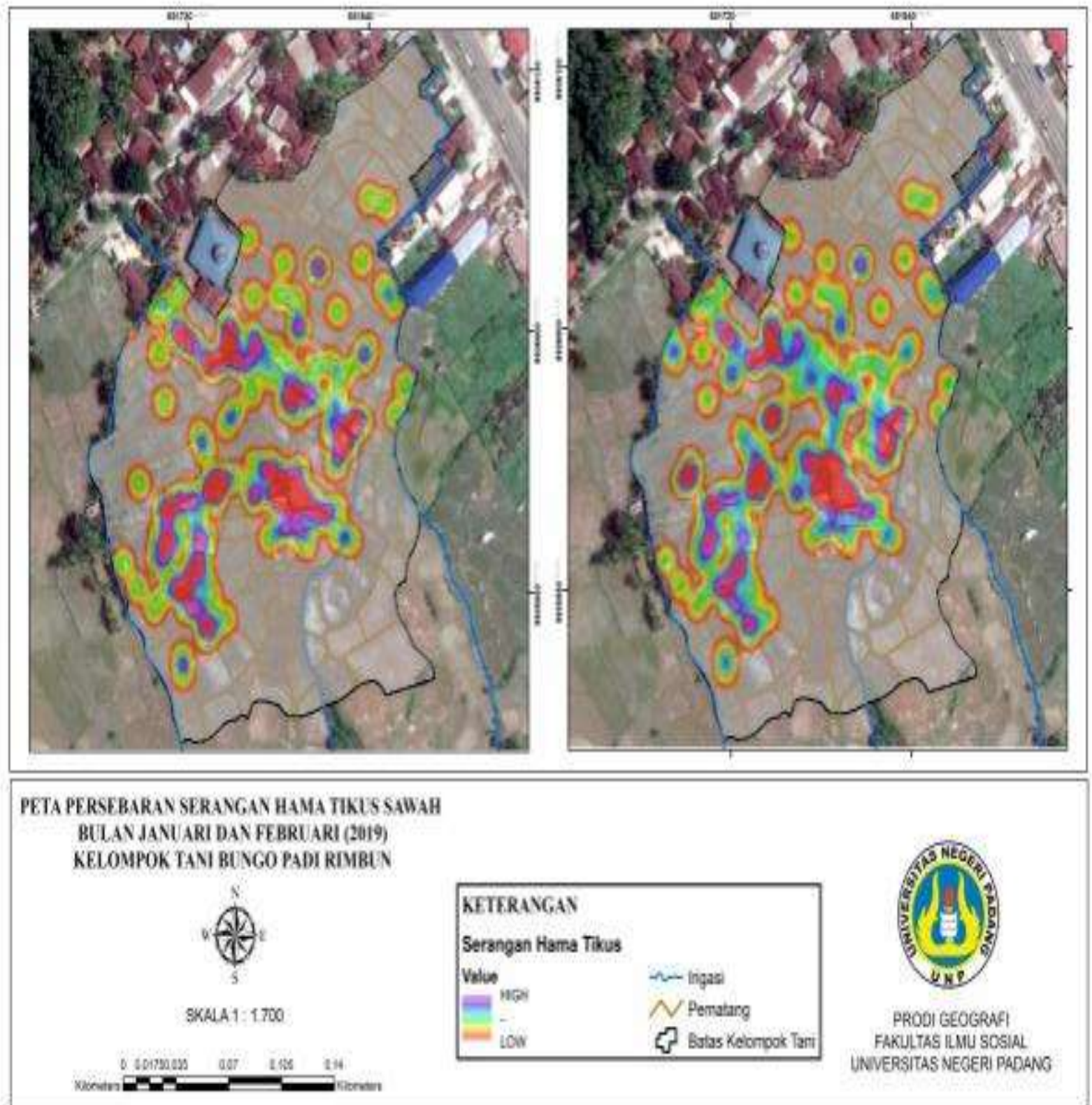

\section{Gambar 2. Peta Kernel Density}

Hasil analisis Spasial kernel density diperoleh sebuah zona bahaya serangan hama tikus. Didalam pengolahan menghasilkan indeks tingkat kerusakan. Sehingga pergerakan serangan hama tikus bisa dilihat secara jelas dengan radius serangan $100 \mathrm{~m}$.

Dari peta di atas dijelaskan bahwa Indeks bewarna merah merupakan daerah yang tingkat kerusakan paling tinggi atau inti, nilai didapat dari perhitungan statistik non parametrik atau dari titik kejadian dan tingkat kerusakan rendah bewarna hijau. Titik kerusakan kecil yang berada disekitar kawasan kerusakan inti merupakan titik selanjutnya serangan hama tikus sawah. Jika dilihat pergerakan nya tidak lah jauh dari kerusakan inti. Sehingga jika dibandikan antar 2 bulan kejadian akan terlihat jelas kerusakan semakin melebar.

Dari perhitungan luas kerusakan didapatkan persentase kerugian :

$$
\text { 45214,8 } \sum_{20915,32 \text { Rusak }} \text { (luas total) }
$$




$$
\begin{aligned}
\% \text { kerusakan } & =\frac{20915,32}{45214,8} \times 100 \\
& =46,258 \%
\end{aligned}
$$

Luas daerah yang mengalami kerusakan dihitung dari hasil zona Kernel Density sehingga dapat melihat luasan daerah dalam satuan meter dan dibandingkan dengan luas sawah kelompok tani Bungo Padi Rimbun. Sehingga diketahui luas kerusakan oleh hama tikus sawah adalah 46,258 \%.

\section{- Hubungan Tingkat Bahaya dengan Kondisi Landscape Ekologi}

Tikus sawah diketahui lebih suka menyerang tanaman padi yang sedang bunting, sehingga pada umumnya padi stadium bunting akan mengalami kerusakan yang paling tinggi. Berdasarkan pengamatan dari malai padi yang dipotong, ternyata hanya beberapa malai saja yang dimakan (Rochman \& Toto, 1976). Kebutuhan pakan tikus setiap hari hanya seberat kurang lebih 10\% dari bobot tubuhnya, sedangkan daya rusaknya terhadap malai padi 5 kali lebih besar dari bobot malai padi yang dikonsumsi.

Jika dihubungkan dengan fisiologis dan tingkah laku dari Tikus Sawah (Rattus argentiventer) maka akan didapatkan pola persebaran kerusakan serangan hama. Ruang gerak setiap hari tikus menempuh perjalanan secara teratur untuk mencari pakan, pasangan, sekaligus orientasi kawasan sekitarnya. Perjalanan harian tersebut menempuh jalan yang sama hingga terbentuk lintasan tetap (run ways). Rentang lintasannya ditentukan oleh jarak pakan, tempat bersembunyi atau lubang. Batas ruang gerak tikus apabila cukup tersedia makanan dan perlindungan, biasanya tidak lebih dari $100 \mathrm{~m}$ dengan menyerang padi dimulai dari tengah sawah, tetapi apabila makanan tidak cukup maka tikus akan bermigrasi dalam jumlah besar dan dapat menjangkau sumber pakan yang berjarak 3-5 km dalam satu malam (Sudarmaji et al. 2010).

Dari peta dapat disimpulkan bahwa pengaruh ekosistem disekitar sawah sangat berpengaruh seperti, irigas dan pematang. Sawah yang paling tinggi tingkat kerusakan nya adalah Sawah yang berada didekat irigasi kotor serta pematang yang penuh ditumbuhi rerumputan. Dari indikator tersebut dapat dilihat fisiologis tikus yang menyenangi daerah tertutup serta kotor sehingga tikus sawah membuat sarang disekitar pematang dan irigasi yang kotor. Peta indikator lingkungan dan serangan hama tikus sawah dapat dilihat pada gambar 3 .

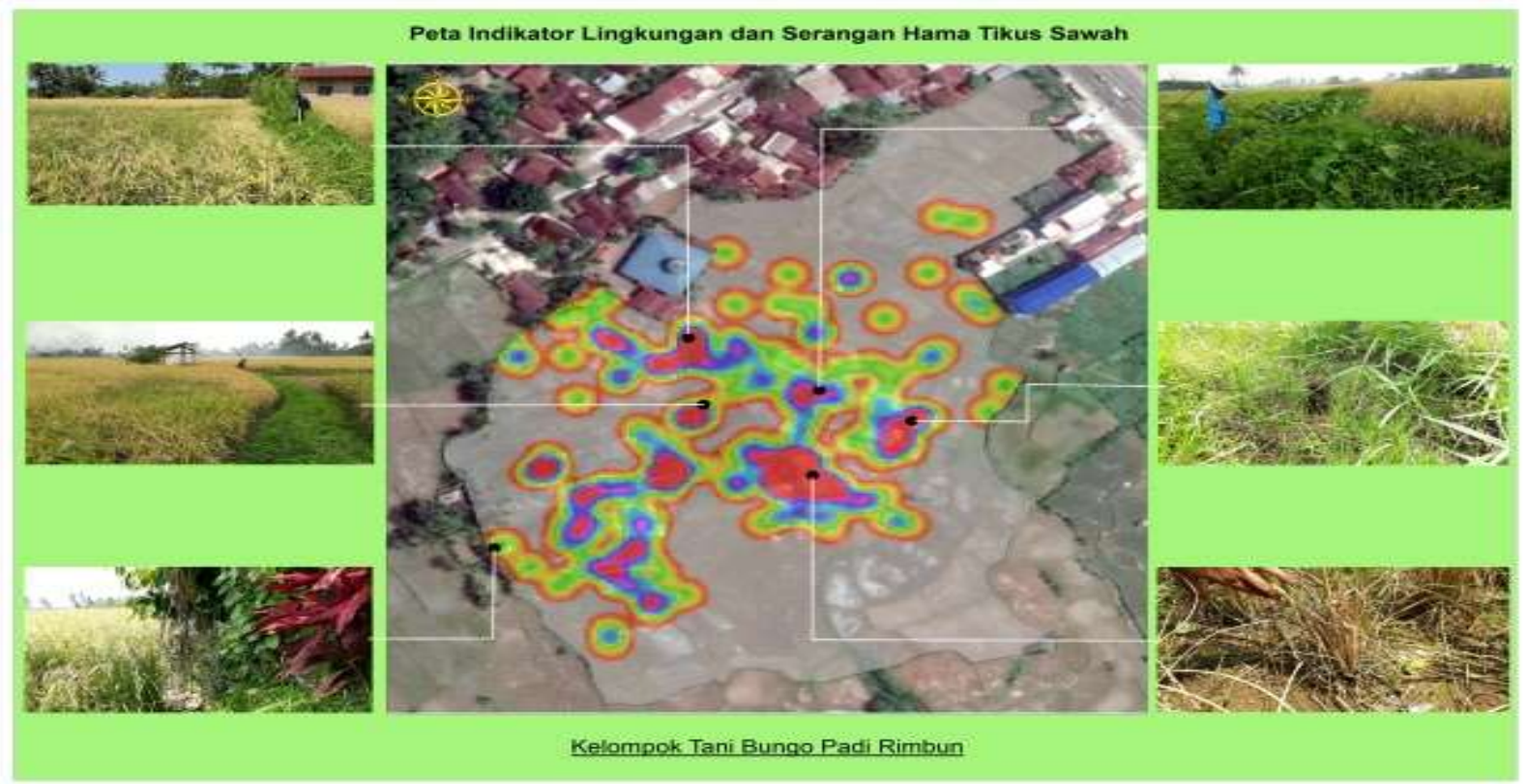

Gambar 3. Peta indikator lingkungan dan ekosistem hama Tikus Sawah 
Sistem pematang sawah sangat berdampak terhadap pertumbuhan populasi tikus sawah karena pematang merupakan tempat untuk tinggal dan berlindung bagi tikus sawah. Pematang yang lebar, tinggi, dan bersemak merupakan tempat yang paling disukai tikus sawah karena di tempat-tempat demikianlah tikusa sawah bersembunyi, melahirkan, dan menyusui anaknya sehingga potenssi pertumbuhan populasi tikus sawah tergantung oleh pematangnya. Kondisi pematang yang ditumbuhi semak tak beraturan dan kotor, mendukung pertambahan populasi tikus sawah dengan sangat pesat.

Irigasi atau pengairan merupakan indikator yang harus diperhatikan karena hal ini berkaitan dengan mobilitas dan tempat bersarangnya tikus di sawah. Sistem irigasi di sawah termasuk sistem irigasi permukaan penggenangan secara terkendali dan melalui Irigasi yang baik akan memberikan dampak yang naik pula terhadap pertumbuhan padi, hal ini mengakibatkan tikus sawah kesulitan utuk mencapai padi. Apabila pematang yang seperti ini terus dibiarkan, maka jumlah tikus sawah akan terus bertambah diiringi dengan pertambahan julah pasokan makannya, yaitu padi, sehingga padi-padi akan terus diserang dan pertumbuhan padi sangat lambat. Hal ini lah yang menyebabkan gagal panen.

Jarak waktu panen, kegiatan panen dilakukan dengan cara yang tidak serempak mengakibatkan ruginya petani yang melaksanakan kegiatan panen yang terlambat. Dengan ketidak samaan waktu panen inilah yang nantinya akan membentu polapola penyerangan hama tikus. Sebelum masa panen, tikus sawah menyerang padi-padi yang terdapat disekitarnya. Namun apabila padi-padi yang ada di sekitar sarang tikus sawah ini dipanen, maka pasokan makanan tikus sawah pun habis sehingga terjadilah pergerakan untuk mencari titik dimana masih terdapat padi yang belum dipanen. Hal ini mengakibatkan adanya pola-pola penyerangan hama tikus.

Terhambatnya pertumbuhan padi yang diakibatkan rusaknya batang padi di bagian pangkalnya. Salah satu tanda yang sangat jelas adalah dengan melihat warna padi yang masih hijau saat musim panen yang mana padi-padi yang lain di sekitarnya sudah menguning. Saat awal menanam atau pertumbuhan awal padi, tikus sawah tersebut juga dapat memakan bibit-bibit padi yang baru ditanam atau padi-padi yang baru menunjukkan pertumbuhan awalnya, dan bahkan menyerang padi yang ada di dalam gudang penyimpanan sehingga sangat memungkinkan gagal panen dapat terjadi saat baru menenanam padi. Salah satu hal yang membuat sangat sulitnya pembasmian hama ini karena tikus aktif menyerang padi pada malam hari.

Pola penanaman juga menjadi indikator yang sangat besar karena apabila tidak kompak dalam menanam dan memanen tentu pasokan makanan untuk tikus selalu tersedia. Sawah yang terakhir memanen akan menjadi bulan bulanan serangan tikus sawah karena itu lah sisa terakhir dari makanan nya. Inilah yang perlu ditekankan kepada para petani untuk lebih kompak dalam waktu penanaman maupun waktu panen.

Dengan adanya peta ini sawah yang rusak diserang hama tikus sawah (Rattus argentiventer) dapat diketahui sehingga bisa diantisipasi kedepannya dengan mitigasi yang baik. Dan memberikan edukasi kepada para petani agar kedepannya serangan hama tikus dapat di minimalisir sekecil mungkin.

\section{KESIMPULAN}

Dari hasil pengolahan Kernel memunculkan zona bahaya hama tikus yang dilihat dari indeks bahayanya, seperti pada peta sebelumnya dijelaskan bahwa warna merah merupakan daerah tingkat kerusakan paling tinggi dan yang bewarna hijau adalah daerah kerusakan kecil hasil, dari perhitungan luas kerusakan didapatkan persentase kegagalan panen sebesar $46,258 \%$. Dengan adanya peta zona serangan hama tikus petani dapat melihat penyebab tinggi nya serangan hama tikus seperti pematang dan irigasi yang kotor belukar maupun penanaman dan pemanenan yang tidak kompak sehingga membuat pasokan makanan bagi hama tikus sawah selalu terjaga. 


\section{DAFTAR PUSTAKA}

Direktorat Bina Perlindungan Tanaman. 1992. Pedoman Pengenalan dan Pengendalian Hama Tikus. Direktorat Jenderal Pertanian Tanaman Pangan. Jakarta. Hal. 1-5, 9-10, 13-14, 16, 42.

Kloog, dkk. 2009. Using kernel density function as an urban analysis tool: Investigating the association between nightlight exposure and the incidence of breast cancer in Haifa, Israel. Computers Environment and Urban Systems. 33, 5563

Rochman S dan Toto A. 2005. Sistem Perangkap Bubu untuk Pengendalian
Tikus di Lahan Sawah dan Rawa. dalam Kumpulan Prosiding Seminar Nasional Hasil Penelitian Menunjang Akselerasi Pengembangan Lahan Pasang Surut. Balitra Banjarbaru.

Sudarmaji, G.R. Singleton, P.R. Brown, J. Jacob, and N.A. Herawati.2010a. Rodent impacts in lowland irrigated intensive ricesystems in West Java, Indonesia. In: Singleton et al. (eds.).Rodent outbreaks: ecology and impacts. International RiceResearch Institute. Los Banos Philippines.p.115-137. 